\title{
The changes in therapeutic and managerial protocols for patients suffering ST-segment elevation myocardial infarction in COVID-19 pandemic; a systematic review and meta-analysis
}

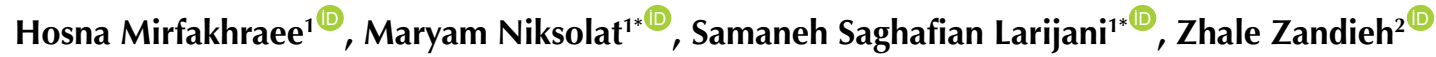 \\ ${ }^{1}$ Research and Clinical Development center of Firoozabadi Hospital, Iran university of medical science, Tehran, Iran \\ ${ }^{2}$ University of Social Welfare and Rehabilitation Sciences, Tehran, Iran
}

\section{Correspondence to: Maryam Niksolatm, Email: Niksolat.m@iums.ac.ir and Samaneh Saghafian Larijani, Email: Saghafian.s@iums.ac.ir}

Received: 5 April 2020 Accepted: 14 November 2020 ePublished: 29 December 2020

Keywords: ST-segment, COVID19, Myocardial infarction

\begin{abstract}
Introduction: Apart from the direct effect of COVID-19 on the incidence of ischemic heart disease, the pandemic effect of this infection on the control of ischemic heart disease and on the clinical consequences of these patients and also their hospital admission is also significant.

Objectives: The present review attempted to assess the admission rate, treatment protocols, and outcome changes in patients suffering ST-segment elevation myocardial infarction (STEMI) in the COVID-19 outbreak. Materials and Methods: The included studies were identified through electronically reviewing the manuscripts databases of MEDLINE, EMBASE, Web of knowledge, and Google Scholar from inception to September 2020. The titles and abstracts of the manuscripts were screened by two blinded reviewers followed by an in-depth assessment of the full texts for assigning the inclusion appropriateness.

Results: Eighteen articles (including 6225 STEMI patients hospitalized within the COVID-19 pandemic duration and 55711 STEMI patients in pre-COVID-19 periods) were desirable for the final analysis. A longer delay among symptom onset and first medical contact (FMC) in the COVID-19 lockdown period than before the COVID-19 pandemic was revealed. Comparing STEMI-related death in the COVID-19 period compared to the pre-COVID-19 duration showed a significantly higher death rate and a higher rate of thrombolytic therapy. The examined pre-COVID-19 and COVID-19 periods showed a reduction in STEMI patients' admissions reached $30.9 \%$. Additionally, entering the COVID-19 period resulted in a significant $44.4 \%$ reduction in the number of primary percutaneous coronary intervention.

Conclusion: During the COVID-19 pandemic, the management of STEMI has undergone significant changes, including reduced hospital admissions, reduced invasive and semi-invasive treatment interventions, increased STEMI-related mortality, increased thrombolytic therapy, and delayed patients' referral to the hospitals.
\end{abstract}

Introduction

Until the end of September 2020, almost 35 million people had been infected with COVID-19, leading to more than one million deaths universal, undoubtedly owing to the onset of the next waves of disease in some regions (1). Usual clinical appearance of the disease includes acute respiratory syndrome with fever and dry cough, dyspnea, fatigue, and myalgia. Approximately $15 \%$ to $20 \%$ of patients experienced severe illness with mortality of about $2 \%$ to $3 \%(2-4)$. In the absence of a vaccine or special treatment, the disease's recognition as rapidly as possible and its severity are essential that can inhibit next improvement of the disease. Along with acute respiratory failure as a prominent and debilitating manifestation of COVID-19, multidimensional organ defects have also

\section{Key point}

During the COVID-19 pandemic, the management of ST-segment elevation myocardial infarction (STEMI) has undergone significant changes, including reduced hospital admissions, reduced invasive and semi-invasive treatment interventions, increased STEMI-related mortality, increased thrombolytic therapy, and delayed patients' referral to the hospitals.

been detected in the affected patients due to the virus triggering role in pro-inflammatory cytokines activation and secretion, as well as coagulation abnormalities $(5,6)$. A complex of such events can predispose the patients to be cardiovascular ischemic and thromboembolic events $(7,8)$. Some clinical data have supported the strong link of COVID-19 infection to cardiac and cerebrovascular ischemic events leading

Copyright $\odot 2020$ The Author(s); Published by Society of Diabetic Nephropathy Prevention. This is an open-access article distributed under the terms of the Creative Commons Attribution License (http://creativecommons.org/licenses/by/4.0), which permits unrestricted use, distribution, and reproduction in any medium, provided the original work is properly cited. 
to high mortality and disabilities (9). This infection is now suggested to promote myocardial injuries leading to cardiac arrhythmias, myocardial hypertrophy, acute coronary syndrome, and even acute heart failure. We obviously see a bidirectional interaction between the cardiovascular system and infection to COVID-19, while the exact mechanisms responsible for such cardiovascular defects remain elusive. Some molecular-based studies emphasize the central role of pro-inflammatory cascades, such as the activation of interleukin- 6 , interleukin-1beta, and tumor necrosis factor- $\alpha$ as the main flaring factors for such events (10). Additionally, the presence of some specific receptors for the virus, such as ACE2, as a gateway for the virus to enter tissues such as the myocardium seems necessary for the mentioned injuries (11). There is also strong evidence on a close association between the effects of the virus and underlying cardiovascular risk factors such as hypertension and diabetes, therefore the presence of any of these risk factors increases the risk of ischemic events many times over $(12,13)$. The body of evidence highlights the high risk of ischemic heart disease such as myocardial infarction in patients with COVID-19. Apart from the direct effect of COVID-19 disease on the incidence of ischemic heart disease, the pandemic effect of this infection on the control of ischemic heart disease, on the clinical consequences of these patients and their hospital admission is also significant. Accordingly, it has been determined that during the outbreak of the disease, we have faced a considerable change in thrombolytic treatment, the time of referral of patients to medical centers, and also their candidacy for revascularization. This is important in two ways. Firstly, given that, especially in developing countries, the majority of hospital admissions are reserved for COVID-19 patients, in practice, admissions of patients with heart disease are significantly reduced. Secondly, the care and treatment protocols of patients with suspected ischemic heart disease have changed considerably despite the risk of concomitant COVID-19 infection. Thus, assessing the management, caring protocols, referring chain, and outcomes of patients with ST-segment elevation myocardial infarction (STEMI) during the COVID-19 pandemic is very necessary.

\section{Objectives}

This review attempted to systematically evaluate the admission rate, treatment protocols, and outcome changes in patients suffering STEMI in the COVID-19 outbreak.

\section{Materials and Methods}

This systematic review and meta-analysis followed the principles of the "Preferred Reporting Items for Systematic Reviews and Meta-Analyses" (PRISMA) guideline (14) (Figure 1). All retrospective or prospective comparative studies assessing the prevalence and risk for STEMI in patients with COVID-19 were desirable for the primary assessment. In this regard, those studies which assessed other cardiovascular events related to this infection were excluded. Studies were selected through electronically reviewing the manuscripts databases of MEDLINE, EMBASE, Web of knowledge, and Google Scholar from inception to September 2020. No language limitation was considered, and thus the non-English manuscripts were tried to translate by a proficient translator to extract the requested data. Two blinded reviewers independently screened the titles and abstracts of the manuscripts, followed by an in-depth assessment of the full texts for

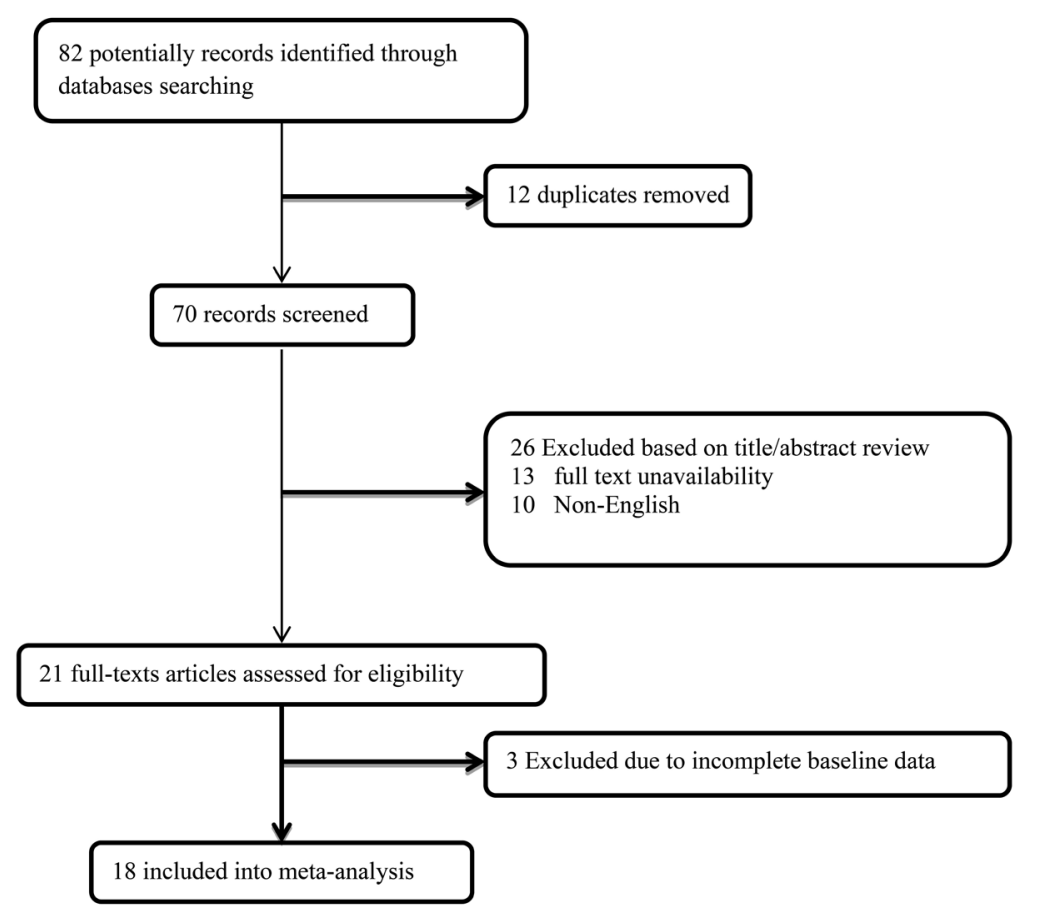

Figure 1. The flowchart of screening the eligible studies. 
distinction of the inclusion appropriateness. In this regard, any disagreement across our reviewers was rechecked by the third reviewer as the final arbitrator. The details of eligibility and the reasons for excluding the papers were shown schematically (Figure 1). After that, the details of the included papers' data were extracted and collected in a pre-established form and ultimately finalized. Before finalizing the meta-analysis, the risk of bias was evaluated blindly by the two authors using the Cochrane risk of bias tool that the level of bias was qualitatively classified as at high, unclear, or low risk of bias (15). To determine the level of bias, the following domains are commonly: how selecting the participants (selection bias), how performing the management of STEMI including hospital admission, thrombolytic therapy, or referring revascularization, how controling confounders and missing data, and how measuring other cardiac-related indexes. The fixed effects or random-effects (in case of significant heterogeneity across the data) models were used to the obtained pooled likelihood of STEMI, followed by reporting 95\% CIs and its-related corresponding $P$ values. The heterogeneity across the studies was assessed by determining $\mathrm{I}^{2}$ and its corresponding $P$ value, indicating the $P$ value of less than 0.05 significant heterogeneity. A sensitivity analysis was accomplished, in which observational studies at acute risk of bias were deprived of the analysis. Publication bias was evaluated by the rank correlation test and confirmed by the funnel plot analysis. Reported values were two-tailed, and hypothesis testing results were considered statistically significant at $P=0.05$. For statistical analysis, the Comprehensive Meta-Analysis Software (CMA, version 3.0) was used.

\section{Results}

The flow diagram of the study selection method is stated in Figure 1. In this text, 82 articles were primarily collected by database searching. Then 12 articles were excluded due to evidence of duplication, so 70 records were primarily under-screened. According to the titles and abstracts, 49 records were excluded, and the residual 21 citations were evaluated for further eligibility. Of those, three were also excluded due to the incompleteness of the data and contents. At least, 18 articles were desirable for the last analysis (16-33). Table 1 illustrates the basic characteristics of the studies included. Evaluation of bias indicated that approximately all studies were considered low risk or with unclear tendencies. So, the results could be considered as reasonable, and none of the citations was dictated to have

Table 1. The baseline details of studies included in our meta-analysis

\begin{tabular}{|c|c|c|c|c|c|}
\hline First Author, Reference & Time point & No. of population & Time interval & Mean age & Male/Female \\
\hline \multirow{2}{*}{ Salarifar (16) } & \multirow{2}{*}{ February-April } & During: 178 & \multirow{2}{*}{$1 y$} & 58.8 & $137 / 41$ \\
\hline & & Before: 146 & & 59.8 & $114 / 32$ \\
\hline \multirow{2}{*}{ Leal (17) } & \multirow{2}{*}{ March-April } & During: 26 & \multirow{2}{*}{$5 y$} & - & - \\
\hline & & Before: 204 & & - & - \\
\hline \multirow{2}{*}{ Abdelaziz (18) } & \multirow{2}{*}{ March-April } & During: 46 & \multirow{2}{*}{$1 y$} & 63.2 & $32 / 14$ \\
\hline & & Before: 69 & & 66.6 & $53 / 16$ \\
\hline \multirow{2}{*}{ Popovic (19) } & \multirow{2}{*}{ February-April } & During: 11 & \multirow{2}{*}{$4 y$} & 62.6 & $7 / 4$ \\
\hline & & Before: 72 & & 59.6 & $53 / 19$ \\
\hline \multirow{2}{*}{ Daoulah (20) } & \multirow{2}{*}{ January-April } & During: 500 & \multirow{2}{*}{$1 y$} & 55.4 & $454 / 46$ \\
\hline & & Before: 635 & & 56.5 & $539 / 96$ \\
\hline \multirow{2}{*}{ Haddad (21) } & \multirow{2}{*}{ March-May } & During: 53 & \multirow{2}{*}{$1 y$} & 60.6 & $44 / 9$ \\
\hline & & Before: 60 & & 69.5 & $42 / 18$ \\
\hline \multirow{2}{*}{ Hammad (22) } & \multirow{2}{*}{ January-April } & During: 35 & \multirow{2}{*}{$1 y$} & 66.0 & $17 / 18$ \\
\hline & & Before: 108 & & 61.8 & $72 / 36$ \\
\hline \multirow{2}{*}{ Kwok (23) } & \multirow{2}{*}{ January-April } & During: 683 & \multirow{2}{*}{$1 y$} & 64.0 & $498 / 185$ \\
\hline & & Before: 33255 & & 63.0 & $24829 / 8426$ \\
\hline \multirow{2}{*}{ Leor (24) } & \multirow{2}{*}{ March-April } & During: 1009 & \multirow{2}{*}{$1 y$} & 63.1 & $786 / 223$ \\
\hline & & Before: 1305 & & 63.7 & $1023 / 282$ \\
\hline \multirow{2}{*}{ Lotfi (25) } & Eebruary-Anril & During: 1038 & & - & - \\
\hline & February-April & Before: 1092 & Ty & - & - \\
\hline & & During: 26 & & 61.00 & $21 / 5$ \\
\hline Di Liberto (26) & March-April & Before: 46 & Ty & 66.00 & $33 / 13$ \\
\hline & & During: 481 & & 65.2 & $357 / 124$ \\
\hline Mesnier (27) & February-April & Before: 686 & Ty & 65.8 & $509 / 177$ \\
\hline & & During: 52 & $1 \mathrm{x}$ & 71.5 & $32 / 20$ \\
\hline Nan (28) & August-March & Before: 158 & Ty & 66.5 & $100 / 58$ \\
\hline & & During: 824 & & 63.5 & $599 / 225$ \\
\hline Natarajan (29) & March-May & Before: 2513 & 1y & 63.6 & $1833 / 680$ \\
\hline & & During:395 & & 61.9 & $317 / 78$ \\
\hline Romaguera (30) & February-March & Before: 524 & 1y & 63.4 & $415 / 109$ \\
\hline & & During:387 & & 64.5 & $277 / 110$ \\
\hline Scholz (31) & March-April & Before: 1329 & $4 y$ & 63.6 & $953 / 376$ \\
\hline Siudle (20) & $\mathrm{M}>\mathrm{rch}$ & During:362 & $1 \times$ & 64.8 & $247 / 111$ \\
\hline Siudak (32) & March-мау & Before: 13388 & ly & 66.9 & $8893 / 4423$ \\
\hline 7 brond (23) & & During:119 & & - & - \\
\hline Zhang (33) & January- March & Before: 121 & $2 y$ & - & - \\
\hline
\end{tabular}


a high risk of bias (Figure 2). Eighteen studies assessed the STEMI patients referred to hospitals within the COVID-19 lockdown period between January and May 2020. Data comparison was made with the same period within 1 to 5 years earlier. STEMI was defined according to the Fourth Universal Definition of Myocardial Infarction guidelines, and overall other studies focusing on non-STEMI or unstable angina were not included in our meta-analysis. As summarized in Table 1, 6225 STEMI patients hospitalized within the COVID-19 pandemic period and 55711STEMI patients in pre-COVID-19 periods were compared regarding STEMI management consequences and cares. The first endpoint of the study was, the clinical outcome of STEMI, and the second was the rate of changes in patients' admission, referring for revascularization within the time points, and comparing the times between symptoms onset and first medical contact (FMC), door-to-balloon time, and also FMC-to-wire crossing. The first pooled analysis led to point remarkably prolonged delays between symptom onset and FMC in the COVID-19 lockdown period as compared to before the COVID-19 pandemic (weighted mean differences of 5.212, 95\% CI: $4.281-6.144, P<0.001$ ), but without the mean difference in door-to-balloon time (weighted mean differences of $0.245,95 \% \mathrm{CI}$ : $-0.171-$ $0.662, P=0.248)$ and the mean difference in FMC-to-wire crossing (weighted mean differences of $0.112,95 \% \mathrm{CI}$ : $-0.123-0.478, P=0.386$; Table 2 ). The heterogeneity across the studies in all measurements was significantly relevant, with the $\mathrm{I}^{2}$ values ranged 96.123 to 98.859 . Comparison of STEMI-related death in the COVID-19 against preCOVID-19 period showed a significantly higher death rate $(\mathrm{HR}=1.399,95 \% \mathrm{CI}: 1.167-1.678, P<0.001$; Figure 3$)$.
However, the rates for repeated revascularization $(\mathrm{HR}=$ $0.861,95 \%$ CI: $0.253-2.923, P=0.810)$, occurrence of non-fatal myocardial infarction $(\mathrm{HR}=3.805,95 \% \mathrm{CI}$ : 0.864-16.855, $P=0.077)$, or requiring rescue PCI $(\mathrm{HR}=$ 1.254, 95\% CI: 0.924-1.704, $P=0.147)$. However, entering the COVID-19 pandemic led to an increase in the rate of thrombolytic therapy $(\mathrm{HR}=1.577,95 \% \mathrm{CI}: 1.027-2.423$, $P=0.037)$. The heterogeneity across the studies in the post-STEMI outcome assessment was also relevant, with the $\mathrm{I}^{2}$ values ranging from 97.246 to 98.456 . Overall, the examined pre-COVID-19 and COVID-19 periods showed a reduction in STEMI patients' admissions reached 30.9\%, ranged from $21.0 \%$ to $51.4 \%$. Additionally, entering the COVID-19 period resulted in a significant $44.4 \%$ (ranged from $20.0 \%$ to $77.6 \%$ ) reduction in the number of primary percutaneous coronary intervention.

\section{Discussion}

Due to the new wave of the COVID-19 and the high volume of referrals of suspected patients to emergency centers, and the need for their hospitalization in normal and ICU wards, there is a fundamental concern about the lack of proper management of other acute diseases, especially cardiovascular disease and cerebrovascular accidents. This concern can be examined from two aspects. Firstly, the possibility of transmitting the disease to other hospitalized patients is very high due to its high transmission rate. Secondly, due to the fear of contracting COVID-19, the number of patients, even patients with acute cardiovascular attacks, is significantly reduced, increasing the mortality rate and morbidity caused by these diseases. On the other hand, due to the mobilization

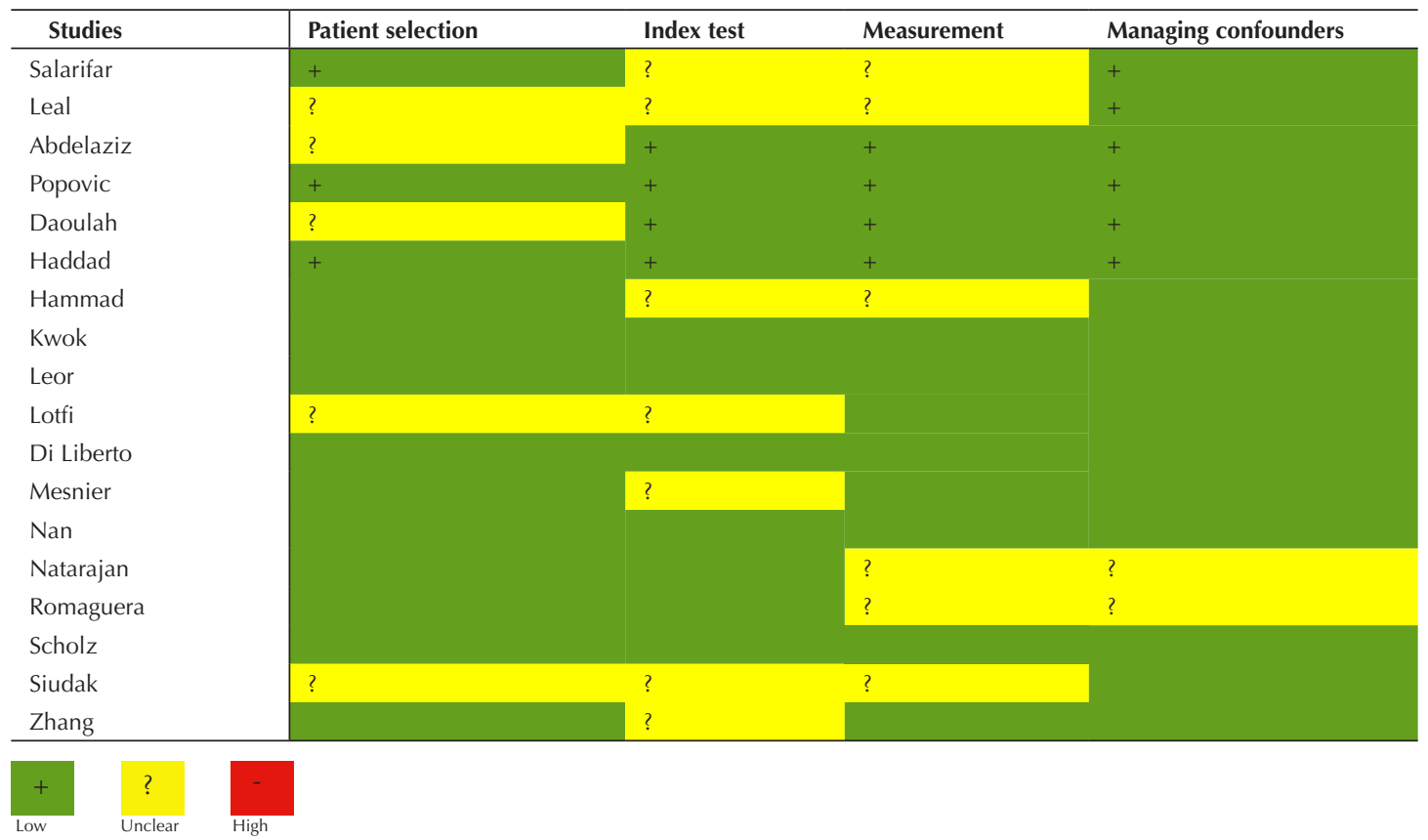

Figure 2. The assessment of the risk of bias. 
Table 2. The time intervals from symptom onset to wire crossing

\begin{tabular}{|c|c|c|c|}
\hline First author & $\begin{array}{l}\text { Symptom onset-to- } \\
\text { FMC (min) }\end{array}$ & $\begin{array}{l}\text { Door-to-balloon } \\
\text { time (min) }\end{array}$ & $\begin{array}{l}\text { FMC-to-wire } \\
\text { crossing (min) }\end{array}$ \\
\hline \multirow{2}{*}{ Salarifar } & 365.50 & 49.50 & 61.00 \\
\hline & 363.00 & 50.00 & 67.50 \\
\hline \multirow{2}{*}{ Leal } & 282.00 & - & 97.00 \\
\hline & 86.00 & - & 68.00 \\
\hline \multirow{2}{*}{ Abdelaziz } & 227.00 & 47.00 & - \\
\hline & 119.00 & 48.00 & - \\
\hline \multirow{2}{*}{ Popovic } & 443.40 & 53.40 & 93.6 \\
\hline & 448.80 & 85.20 & 149.4 \\
\hline \multirow{2}{*}{ Haddad } & 189.00 & 63.00 & 102.00 \\
\hline & 103.00 & 71.00 & 104.00 \\
\hline \multirow{2}{*}{ Hammad } & - & 58.00 & 148 \\
\hline & - & 59.00 & 130 \\
\hline \multirow{2}{*}{ Kwok } & 150.00 & 48.00 & - \\
\hline & 135.00 & 37.00 & - \\
\hline \multirow{2}{*}{ Leor } & 105.00 & - & 110.00 \\
\hline & 71.00 & - & 110.00 \\
\hline \multirow{2}{*}{ Lotfi } & 180 & 66.00 & - \\
\hline & 142 & 65.00 & - \\
\hline \multirow{2}{*}{ Mesnier } & 180 & - & - \\
\hline & 180 & - & - \\
\hline \multirow{2}{*}{ Nan } & 188 & 77 & - \\
\hline & 157 & 50 & - \\
\hline \multirow{2}{*}{ Romaguera } & 160 & 22.0 & - \\
\hline & 141 & 20.0 & - \\
\hline \multirow{2}{*}{ Scholz } & 163 & 39.9 & 91.3 \\
\hline & 150 & 39.4 & 92.6 \\
\hline \multirow{2}{*}{ Siudak } & 249 & - & 141 \\
\hline & 226 & - & 111 \\
\hline \multirow{2}{*}{ Zhang } & 230 & 72 & 94 \\
\hline & 91 & 57 & 46 \\
\hline
\end{tabular}

of medical staff against the COVID-19, almost all the energy and power of medical and nursing staff, especially in developing countries, have been spent combating the COVID-19 disease, causing less attention paid to other major diseases. Additionally, some physicians fear that invasive and semi-invasive diagnostic and therapeutic interventions, such as revascularization, may increase the possibility of transmitting the virus to both patients

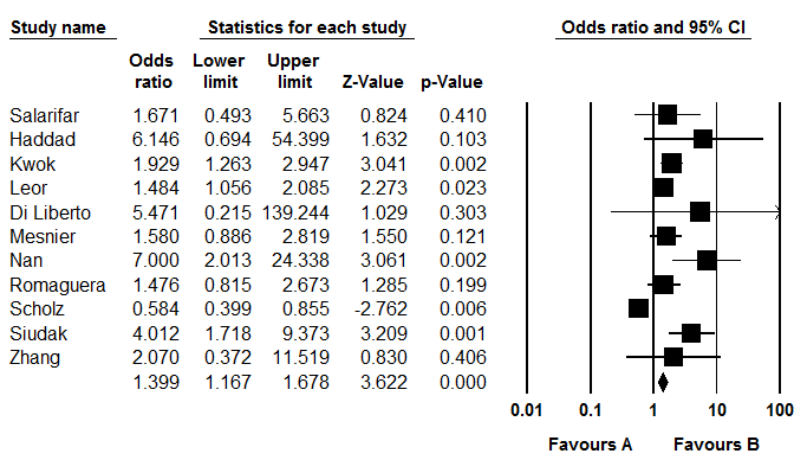

Figure 3. The hazard ratio in post-STEMI death in the pooled assessment of the studies. and staff. For this reason, they have very little desire to perform such interventions in hospitals. Therefore, it can be expected to reduce hospital admissions for patients with cardiovascular disease and reduce invasive treatment interventions for these patients. What was concluded in the present study could be examined from several points. Firstly, in the COVID-19 pandemic period compared to the pre-COVID-19 period, we have seen a significant decrease in hospital admissions and invasive treatment of patients with STEMI, which was entirely predictable based on the above explanations. Secondly, the rate of thrombolytic therapy has increased significantly during this period due to the disease's acceptable response to thrombolytic therapies; its development has been very effective. Therefore, the tendency of physicians to use these treatment protocols is high. However, deaths from cardiovascular disease have also increased dramatically, perhaps due to the fear of timely referral to medical facilities for fear of developing COVID-19 disease. Studies also show that COVID-19 disease has an intense conflict with STEMI. However, another critical point from this study is that there is a significant delay between the onset of symptoms of a heart attack and the first visit and contact with medical centers, which shows a considerable delay in the COVID-19 pandemic period compared to the previous period. In fact, the lack of sufficient awareness of patients about the need to contact medical centers as soon as possible for proper heart disease management (probably again due to co-infection with COVID-19) is the reason for such a delay. Overall, it can be said that both patients with heart attack are less inclined to use medical services in medical centers, especially in the referral centers for COVID-19 patients, and physicians are willing not to perform invasive treatment interventions for these patients. Such a result could be specific to the Iranian population because the country is struggling with the third wave of COVID-19 and has almost mobilized its health care system to serve patients with COVID-19. Therefore the simultaneous management of COVID-19 and other major illnesses such as STEMI is challenging.

\section{Authors' contribution}

$\mathrm{HM}$ and $\mathrm{MN}$ were the principal investigators of the study, $\mathrm{ZZ}$ and SSL were included in preparing the concept and design. All authors participated in preparing the final draft of the manuscript, revised the manuscript and critically evaluated the intellectual contents. All authors have read and approved the content of the manuscript and confirmed the accuracy or integrity of any part of the work.

\section{Conflicts of interest}

The authors declare that they have no competing interests.

Ethical considerations

Ethical issues (including plagiarism, data fabrication, double publication) have been completely observed by the authors.

\section{Funding/Support}

None. 


\section{References}

1. Wu Z, McGoogan JM. Characteristics of and Important Lessons From the Coronavirus Disease 2019 (COVID-19) Outbreak in China: Summary of a Report of 72314 Cases From the Chinese Center for Disease Control and Prevention. JAMA. 2020;323:1239-42. doi: 10.1001/jama.2020.2648.

2. Guan WJ, Ni ZY, Hu Y, Liang $W H$, Ou CQ, et al. China Medical Treatment Expert Group for Covid-19. Clinical Characteristics of Coronavirus Disease 2019 in China. N Engl J Med. 2020;382:1708-20. doi: 10.1056/NEJMoa2002032

3. Huang C, Wang Y, Li X, Ren L, Zhao J, Hu Y, et al. Clinical features of patients infected with 2019 novel coronavirus in Wuhan, China. Lancet. 2020;395:497-506. doi: 10.1016/ S0140-6736(20)30183-5

4. Ai T, Yang Z, Hou H, Zhan C, Chen C, Lv W, et al. Correlation of chest CT and RT-PCR testing for coronavirus disease 2019 (COVID-19) in China: a report of 1014 cases. Radiology. 2020;296:E32-40. doi: 10.1148/radiol.2020200642

5. Tay MZ, Poh CM, Rénia L, MacAry PA, Ng LFP. The trinity of COVID-19: immunity, inflammation and intervention. Nat Rev Immunol. 2020;20:363-74. doi: 10.1038/s41577-020-0311-8

6. Bikdeli B, Madhavan MV, Jimenez D, Chuich T, Dreyfus I, Driggin E, et al. Global COVID-19 Thrombosis Collaborative Group, endorsed by the ISTH, NATF, ESVM, and the IUA, supported by the ESC Working Group on Pulmonary Circulation and Right Ventricular Function. COVID-19 and Thrombotic or Thromboembolic Disease: Implications for Prevention, Antithrombotic Therapy, and Follow-Up: JACC State-of-the-Art Review. J Am Coll Cardiol. 2020;75:2950-73. doi: 10.1016/j.jacc.2020.04.031

7. Connors JM, Levy JH. Thromboinflammation and the hypercoagulability of COVID-19. J Thromb Haemost. 2020;18:1559-61. doi: 10.1111/jth.14849

8. Madjid M, Safavi-Naeini P, Solomon SD, Vardeny O. Potential effects of coronaviruses on the cardiovascular system: a review. JAMA Cardiol. 2020;5:831-40. doi: 10.1001/ jamacardio.2020.1286

9. Clerkin KJ, Fried JA, Raikhelkar J, Sayer G, Griffin JM, Masoumi A, et al. COVID-19 and cardiovascular disease. Circulation. 2020;141:1648-55. doi: 10.1161/ CIRCULATIONAHA.120.046941

10. Riphagen S, Gomez X, Gonzalez-Martinez C, Wilkinson N, Theocharis P. Hyperinflammatory shock in children during COVID-19 pandemic. Lancet. 2020;395:1607-8. doi: 10.1016/S0140-6736(20)31094-1

11. Oudit GY, Kassiri Z, Jiang C, Liu PP, Poutanen SM, Penninger $J M$, et al. SARS-coronavirus modulation of myocardial ACE2 expression and inflammation in patients with SARS. Eur J Clin Invest. 2009;39:618-25. doi: 10.1111/j.13652362.2009.02153.x

12. Huang C, Wang Y, Li X, Ren L, Zhao J, Hu Y, et al. Clinical features of patients infected with 2019 novel coronavirus in Wuhan, China. Lancet. 2020;395:497-506. doi: 10.1016/ S0140-6736(20)30183-5

13. Wu Z, McGoogan JM. Characteristics of and important lessons from the coronavirus disease 2019 (COVID-19) outbreak in China: summary of a report of 72314 cases from the Chinese Center for Disease Control and Prevention. JAMA. 2020;323(13):1239-42. doi: 10.1001/jama.2020.2648

14. Liberati A, Altman DG, Tetzlaff J, Mulrow C, Gøtzsche PC, loannidis JP, et al. The PRISMA statement for reporting systematic reviews and meta-analyses of studies that evaluate healthcare interventions: explanation and elaboration. BMJ. 2009;339:b2700. doi: 10.1136/bmj.b2700

15. Higgins JPT, Altman DG, Sterne JAC. Chapter 8: Assessing risk of bias in included studies. IN: Higgins JPT, Green S, eds.
Cochrane Handbook for Systematic Reviews of Interventions version 520. Cochrane; 2017.

16. Salarifar M, Ghavami M, Poorhosseini H, Masoudkabir F, Jenab Y, Amirzadegan A, et al. The impact of a dedicated coronavirus disease 2019 primary angioplasty protocol on time components related to ST-segment elevation myocardial infarction management in a $24 / 7$ primary percutaneous coronary intervention-capable hospital. Kardiol Pol. 2020;78:1227-34. doi: 10.33963/KP.15607

17. Rebollal-Leal F, Aldama-López G, Flores-Ríos X, PiñónEsteban P, Salgado-Fernández J, Calviño-Santos R, et al. Impact of COVID-19 outbreak and public lockdown on STsegment elevation myocardial infarction care in Spain. Cardiol J. 2020;27:425-6. doi: 10.5603/CJ.a2020.0098

18. Abdelaziz HK, Abdelrahman A, Nabi A, Debski M, Mentias A, Choudhury T, et al. Impact of COVID-19 pandemic on patients with ST-segment elevation myocardial infarction: Insights from a British cardiac center. Am Heart J. 2020;226:45-8. doi: 10.1016/j.ahj.2020.04.022

19. Popovic B, Varlot J, Metzdorf PA, Jeulin H, Goehringer F, Camenzind $\mathrm{E}$. Changes in characteristics and management among patients with ST-elevation myocardial infarction due to COVID-19 infection. Catheter Cardiovasc Interv. 2020. doi: 10.1002/ccd.29114.

20. Daoulah A, Hersi AS, Al-Faifi SM, Alasmari A, Aljohar A, Balghith M, et al. STEMI and COVID-19 Pandemic in Saudi Arabia. Curr Probl Cardiol. 202;46:100656.. doi: 10.1016/j. cpcardiol.2020.100656

21. Haddad K, Potter BJ, Matteau A, Gobeil F, Mansour S. Implications of COVID-19 on time-sensitive STEMI care: A report from a North American epicenter. Cardiovasc Revasc Med. 2020 Sep 19:S1553-8389(20)30573-X. doi: 10.1016/j. carrev.2020.09.024

22. Hammad TA, Parikh M, Tashtish N, Lowry CM, Gorbey D, Forouzandeh F, et al. Impact of COVID-19 pandemic on STelevation myocardial infarction in a non-COVID-19 epicenter. Catheter Cardiovasc Interv. 2020 Jun 1:10.1002/ccd.28997. doi: 10.1002/ccd.28997

23. Kwok CS, Gale CP, Kinnaird T, Curzen N, Ludman P, Kontopantelis E, et al. Impact of COVID-19 on percutaneous coronary intervention for ST-elevation myocardial infarction. Heart. 2020;106:1805-11. doi: 10.1136/heartjnl-2020-317650

24. Rodríguez-Leor O, Cid-Álvarez B, Pérez de Prado A, Rossello X, Ojeda S, Serrador A, et al. Impact of COVID-19 on STsegment elevation myocardial infarction care. The Spanish experience. Rev Esp Cardiol (Engl Ed). 2020;73:994-1002. English, Spanish. doi: 10.1016/j.rec.2020.08.002

25. Lotfi AS, Capatina A, Kugelmass AD. Assessment of ST-segment elevation myocardial infarction volume trends during the COVID-19 Pandemic. Am J Cardiol. 2020;131:132-3. doi: 10.1016/j.amjcard.2020.06.029.

26. Di Liberto IA, Pilato G, Geraci S, Milazzo D, Vaccaro G, Buccheri S, et al. Impact on hospital admission of STelevation myocardial infarction patients during coronavirus disease 2019 pandemic in an Italian Hospital. J Cardiovasc Med (Hagerstown). 2020;21:722-4. doi: 10.2459/ JCM.0000000000001053

27. Mesnier J, Cottin Y, Coste P, Ferrari E, Schiele F, Lemesle G, et al. Hospital admissions for acute myocardial infarction before and after lockdown according to regional prevalence of COVID-19 and patient profile in France: a registry study. Lancet Public Health. 2020;5:e536-42. doi: 10.1016/S24682667(20)30188-2.

28. Nan J, Meng S, Hu H, Jia R, Chen W, Li Q, et al. Comparison of clinical outcomes in patients with ST elevation myocardial infarction with percutaneous coronary intervention and the 
use of a telemedicine app before and after the COVID-19 pandemic at a center in Beijing, China, from August 2019 to March 2020. Med Sci Monit. 2020;26:e927061. doi: 10.12659/MSM.927061

29. Natarajan MK, Wijeysundera HC, Oakes G, Cantor WJ, Miner SES, Welsford M, et al. Early observations during the COVID-19 pandemic in cardiac catheterization procedures for ST-elevation myocardial infarction across Ontario. CJC Open. 2020;2(6):678-683. doi: 10.1016/j.cjco.2020.07.015

30. Romaguera R, Ribera A, Güell-Viaplana F, Tomás-Querol C, Muñoz-Camacho JF, Agudelo V; Codi IAM investigators. Decrease in ST-segment elevation myocardial infarction admissions in Catalonia during the COVID-19 pandemic. Rev Esp Cardiol (Engl Ed). 2020;73:778-80. doi: 10.1016/j. rec.2020.06.001
31. Scholz KH, Lengenfelder B, Thilo C, Jeron A, Stefanow S, Janssens $\mathrm{U}$, et al. Impact of COVID-19 outbreak on regional STEMI care in Germany. Clin Res Cardiol. 2020;109:1511-21. doi: 10.1007/s00392-020-01703-Z

32. Siudak Z, Grygier M, Wojakowski W, Malinowski KP, Witkowski A, Gąsior $M$, et al. Clinical and procedural characteristics of COVID-19 patients treated with percutaneous coronary interventions. Catheter Cardiovasc Interv. 2020;96:E568-E575. doi: $10.1002 / \mathrm{ccd} .29134$

33. Zhang F, Song X, Dang Y. Experience of ST segment elevation myocardial infarction management during COVID-19 pandemic from the mainland of China. Cardiovasc Revasc Med. 2020:S1553-8389(20)30453-X. doi: 10.1016/j. carrev.2020.07.027 